\title{
Evaluation of English and Information Technology Skills of New Entrants to Sri Lankan Universities
}

\author{
G. N. Wikramanayake, Member, IACSIT, Damitha D. Karunartna, and Dilkushi S. Wettewe
}

\begin{abstract}
This study presents our experiences in designing, implementing and deploying an on-line evaluation scheme to measure the English and information technology skills of new entrants to Sri Lankan universities at point of entry in 2011. Over 15,000 students from 25 districts of the country were subjected to the on-line evaluation. The test was conducted by using a learning management system, in 24 consecutive days in twenty six centres scattered across the country. This paper sums up the experiences we gathered in conducting the evaluation of a larger group of students spread across a wide geographical area and the lessons learned.
\end{abstract}

Index Terms - Assessment, blended learning, evaluation, skills.

\section{INTRODUCTION}

In Sri Lanka after obtaining secondary education in one of the two local languages, namely Sinhala or Tamil, around 22,000 students enter 15 universities located island wide to follow over 220 degree programmes offered under the government free education programme annually. There is high demand and competition among students for university entrance. In the year 2010 only $17.2 \%$ of qualified students were able to secure a place in a university [1]. Due to the change in the language used for learning, a large number of students required further training in English. Also due to lack of resources at schools, the Information Technology (IT) knowledge of these students at the time of entering the universities is well-below the level required. Also, there are not many students who either own a computer or had a chance to use computers before.

The Ministry of Higher Education (MOHE) in Sri Lanka, in an effort to upgrade the English and IT skills of the new entrants, introduced a pre-orientation programme (POP) in 2011 which included English and IT skills [2]. The aim was to conduct an intensive training programme in English and IT over a period of 3 months for students selected to follow university degree programmes. The main objective of the training programme in English and IT was to elevate the current knowledge of English and IT of university entrants and enhance their ability to use them effectively for academic success at the university level. Over the last few years training programmes spanning over 4 weeks were carried out by respective universities to improve both the English and IT

Manuscript received December 10, 2011; revised April 10, 2012. This work was support by MOHE, HETC Project and NODES centres'.

Gihan N. Wikramanayake and Damitha D. Karunartna is with the University of Colombo School of Computing, Colombo, Sri Lanka (e-mail: gnw@ucsc.cmb.ac.lk, ddk@ucsc.cmb.ac.lk).

Dilkushi S. Wettewe is with the University of Kelaniya, Kelaniya, Sri Lanka (e-mail: dilkush25 @ hotmail.com). knowledge of students after admitting to the universities. After identifying that the students require at least 3 months training to improve English and IT, a methodology was developed to identify the weak students who are eligible for university entrance and to train them both in English and IT prior to their admission to the universities. Two of the main problems to be solved in implementing this project were to identify the weak students from the large number of prospective university students reside at every corner of the country within few days and to train them locally by using local resources rather than bring them to a central location which was not feasible due to various constraints.

Results of such tests will definitely guide teachers and policy makers in recognizing learner goals and redesigning and strengthening syllabuses for future English and IT undergraduate courses. Several studies [3], [4] have documented the positive impacts of national examinations on improving curricula and teaching and learning methods.

\section{Methodology}

The constant use of the Internet and the World Wide Web has inspired many teachers, moderators and trainers to work with students using the computer. Working with networked and multimedia technology not only enhances the IT knowledge of students but also their English Language skills. In the foreseeable future, academics and English language teachers will have to take a closer look at aligning assessments schemes with courses that are offered online as well as using the traditional method (which will have some online components).

Indeed, assessments are believed to be the 'engine that drives and motivates' students [5]. It is now believed that highly networked organizations such as professional associations are recognizing the huge potential of 'any time, any place' assessment schemes [6]. Online assessments are definitely revolutionary and offer more opportunities for students to benefit from the own learning. As we are bending more and more toward learner-centred teaching and learning, developing assessments with the use of multimedia technology will provide teachers and academics with new methods of assessments.

The design of assessments to evaluate the student progress was based on formative assessments [7] with respect to the curriculum of the courses and the objectives of the programme. Multiple Choice Questions (MCQs) were the main types of questions and this form of testing was successfully used for the BIT programme of the university [8]. In this programme we showed that MCQ could be used to assess skills in courses such as "PC Applications" in which 
knowledge and skill of general application packages were evaluated [9]. Whether it is an online or face-to-face (f2f) course, the assessment of those who have followed the course is very important to certify their learning [10]. Formative assessments were ideal for our target group.

There is no doubt about the vital role of examinations in determining language policy and planning as they introduce ways of reforming syllabuses, existing teaching methods etc. The definitions and aims of language planning have been the subject of much debate [11]. Fasold [12] observes that the term implies that certain choices will be made about language behaviour. In language planning and policy, one of the first steps is to discover more information of the target population, their social distribution and the status of languages used [13]. In addition, successfully conducted national examinations pave to measure developed competencies, abilities and skills of the target population. National assessments schemes act as an important instrument to identify factors that will impact language policy and planning in a country and in turn shape the education system. In this backdrop, nationally conducted online examinations are definitely agents of change in the education system of a country.

To assess the English and IT skills of the new entrants to Sri Lankan universities the following techniques were used:

- A situational analysis with stakeholders to develop content for the tests and course

- Pre-test for English to assess English language skills at point of entry

- Pre-test for IT to assess IT skills at point of entry

A situational analysis was conducted with stakeholders namely ministry officials, university officials and lecturers to develop the assessment techniques, the course content and mechanism for a specific target population and to identify the possible regional centres where the course and the online tests can be conducted.

After the situational analysis, it was decided to coordinate this training centrally, and to assess and train all weak students using regional centres. Each training programme was designed to be delivered over 12 weeks covering 4 hours of learning for each subject (English and IT) per week for each selected student. Training was supplemented with take home assignments for students.

\section{A. English Course}

In addition to the 48 hours of teaching and learning that the students experienced by following the orientation course, the English component also offered a listening component comprising of 12 extra hours. A student book plus a teachers' guide were developed for the English component. The objectives of the English component were many. It aimed to develop the new entrants use of English in day to day activities, in informal and formal conversations, for academic reading and writing purposes, to enhance the students' listening skills and finally to enable the new entrants to function effectively in their chosen academic fields.

The course content for the English component contained an integrated approach where all the skills such as reading, writing, speaking, vocabulary, grammar and listening were incorporated. Each lesson also contained a separate listening activity based on the respective topics. In addition, the
English component was accessible to students as a blended online course. In any case, the listening component was accessible only as an online task. This was so designed to enhance the students' use and knowledge of IT skills even within English.

\section{B. IT Course}

The entire IT component was offered to students online with facilitators at the regional centre trained to guide the students. An average user was expected to complete the course within 45 hours and the curriculum covered the content of a typical information technology driving license level [14], which includes working with a computer, Internet services, word processing applications, preparing presentations and data analysis using spreadsheet applications. The study material of the course was developed and made available on-line, in a Course Management System (CMS) for both student and trainers. A question base was provided to conduct an on-line test after completing the course to access the student's achievement. The open source software application Moodle [15] was used as the CMS to deliver the course content.

Through this method of delivery, each centre was able to offer training for 10 batches of students. Thus having a training centre in each district in the country, it was possible to cover more than $50 \%$ of the target group. The sole objective of the pre-tests was to identify weak students to be placed at the limited region centres. The regional centres enabled access to English and IT knowledge for all university entrants and to determine how factors like location and gender affect on their knowledge. Online courses were prepared and deployed on a central server for both courses for all students which can be access anytime from anywhere from the country. The on-line courses comprised of a spectrum of learning resources such as student manuals, references, activities and quizzes. These on-line courses were aimed at students with reasonably good knowledge in IT to follow the programme at their own pace from anywhere using the online material. As large number of students may not have used a computer before, the pre-test was designed using multiple choice questions to check their basic skills.

The assessment of the English and IT skills of the new entrants through supervised online pre-test was held for the first time in June 2011. It was the first instance of an online test that has been administered island wide to assess skills of tens of thousands of students.

\section{English Test}

To design a test that would reveal the English competences of all the new entrants was an extremely difficult task. The test was designed to gauge not only the reading, vocabulary and grammar skills of the students but also their written competencies. Hence, the English evaluation technique consisted of four components. The four components were designed to evaluate the reading, grammar, vocabulary and writing skills of the new entrants. The English evaluation technique was based on UTEL (University Test of the English Language, Sri Lanka) Level 4 (a benchmark scheme modelled on IELTS - International English Language Testing System [16]). The English evaluation technique 
mainly focused on pre-intermediate English language skills. The adoption of UTEL benchmark 4 was because, in the situational analysis that was conducted, it was revealed that undergraduates of Sri Lankan universities were expected to be at a minimum of UTEL 5 when they graduate. Hence, the orientation course and the assessment techniques were modelled on benchmark UTEL 4.

\section{IT Test}

The IT evaluation technique consisted of modules focusing on computer driving licence level [14]. The pre-test was administered by the National Online Distance Education Services (NODES) [2] of the government of Sri Lanka and was conducted in 26 centres around the country including the North and the East. The duration of the tests was two hours (1 hour for English and 1 hour for IT). The new entrants were asked to register on-line for the pre-test prior to sitting for it.

\section{DifFICULTIES FACED}

One of the main difficulties faced in conducting the test was the uneven distribution of students across different districts and the availability of test centres to conduct the examination (Fig. 1a). Thus difficulties were faced in assigning students to their closest examination centres resulting uneven allocation of students in each examination date. Another challenge was to encourage and access the students who have never used computers before. Through media students were encourage online booking to enrol for online test. Facilitators at regional centres were trained to assist in the entire process including subsequent training and evaluations using online material. Due to the lack of knowledge of students on on-line examinations resulted in many students pressing wrong keys and terminating their sessions accidently. Thus in the first few days, students actions were carefully monitored and the Moodle quiz module was customized to minimize the unintended actions during the examinations. Also, all examination centres were monitored real time through video-conferencing facilities and the supervisions at the examination centres were instructed to educate the students on common mistakes prior to starting the examination. Out of the 22,000 who were offered training about $30 \%$ didn't take part as they were not ready to take up the opportunity or they were unaware of the programme.

\section{RESULTS}

The test was conducted by using Moodle CMS, in 24 consecutive days in twenty six centres scattered across the country. Over 15,000 students from 9 provinces and 25 districts of the country were subjected to the on-line evaluation. Performance in these tests is given in Fig. 1b. After considering many factors and the expected outcome the pass marks for the IT and English were set as 40 and 80 respectively.

\section{CONCLUSION}

The implementation of the project validated the effectiveness of the approach employed. Also, the findings of the study revealed students' competence in IT and English skills prior to entering the Sri Lankan universities. The findings also revealed whether there were significant differences between students in urban city areas and rural areas in Sri Lanka. Based on the results of the study, this study determined the student population at pre-intermediate level, below and above in both IT and English skills. The purpose for such categorization was to exclude students who are above the pre-intermediate level and to focus on the students who are below that level for further training. Our findings have already provided significant insights for the designing and implementing mass scale distributed on-line evaluations and for course designers and teachers of IT and English undergraduate courses in Sri Lankan universities.

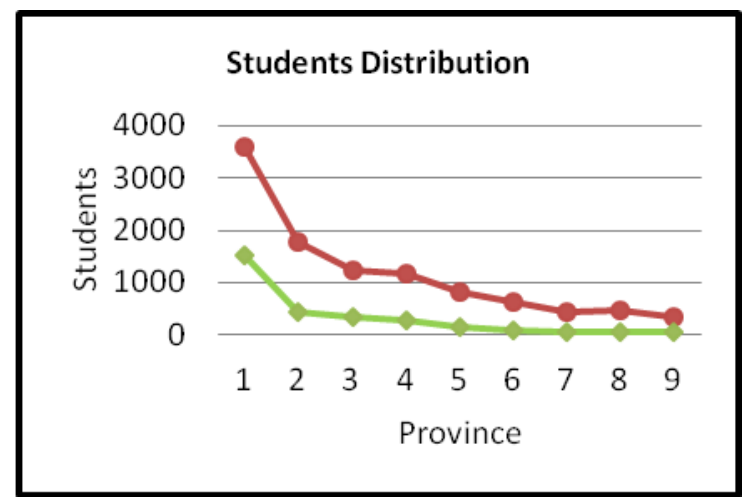

Fig. 1. (a) Students for IT and english by province.

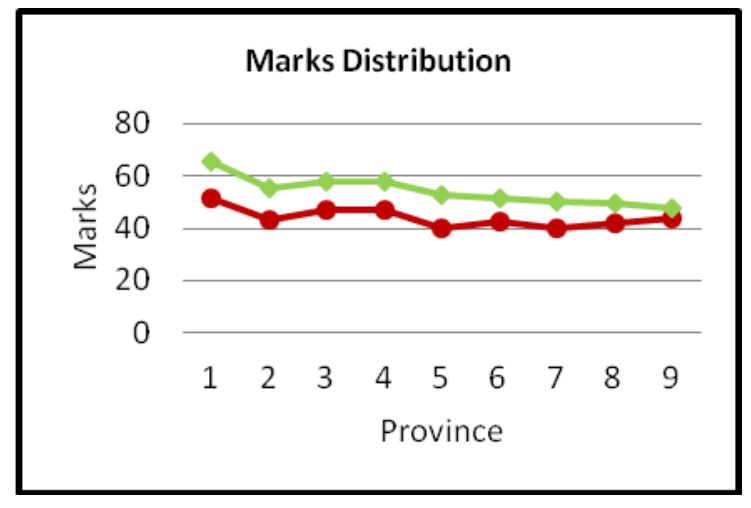

Fig. 1. (b) Marks for IT and english by province.

$$
\leadsto \text { IT } \leadsto \text { English }
$$

\section{ACKNOWLEDGMENT}

This work was support by MOHE, HETC Project and NODES centres'.

\section{REFERENCES}

[1] Summary university education statistics of Sri Lanka.[Online]. Available:

http://www.ugc.ac.lk/en/statistics/university-statistics-2010.html

[2] Pre-orientation Programme for New Entrants to Universities.[Online] Available: http://pop.nodes.lk/

[3] J. J. Lee, Language Testing as a Technique to Enhance EFL Teaching Effects on Vocabulary Acquisition at the Intermediate Level. Faculty of Education. Philadelphia: The Pensylvania State University, 2000. 
[4] T. Kellaghan, Examination Systems in Africa: Between Internationalisation and Indigenisation. Examinations: Comparative and International Studies. M. Eckstein and H. Noah. Oxford: Pergamon Press, 1992.

[5] S. Brown, P. Bull, and J. Race, Computer-assisted assessment in higher education. London: Kogan Page, 1999.

[6] G. Salmon, E-moderating: The key to teaching and learning online. Routkedge, 2000.

[7] D. Nicol, "E-assessment by design: using multiple-choice tests togood effect," J. Further and Higher Education, vol. 31, no. 1, pp. 53-64, 2007.

[8] G. N. Wikramanayake, K. P. Hewagamage, G. I. Gamage, and A. R. Weerasinghe, "Asia eBIT @ UCSC: Implementing the paradigm shift from Teaching to Learning through e-learning framework," 25th National IT Conf, Colombo, Sri Lanka; 2007, pp. 68-81.

[9] K. P. Hewagamage, and G. N. Wikramanayake, "Designing Formative e-Assessments to Prepare Students for the Summative Assessment in Massive Online Courses," Intl. J. of Information and Education Technology, vol. 1, no. 4, pp. 286-291, 2011.

[10] Maddalena Taras, "Assessment - Summative and Formative -Some theoretical Reflections," British J. Educational Studies, vol. 53, no. 4 pp. 466-478, 2005.

[11] M. C. Jones, and I. Singh, Exploring language change. Routledge, 2005.

[12] R. Fasold, The sociolinguistics of society. Oxford: Blackwell, 1984, p. 246.

[13] R. Appel and P. Muysken, Language Contact and Bilingualism. Amsterdam University Press, 2005, p. 50

[14] ICDL an international computer skills certification programme. [Online]. Available: http://www.ecdl.org/

[15] Moodle Open Source Course Management System. [Online]. Available: http://moodle.org/

[16] IELTS - International English Language Testing System. [Online]. Available: http://www.ielts.org/

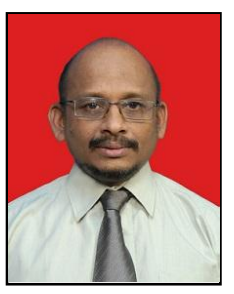

Prof. Gihan N. Wikramanayake obtained his B.Sc degree in Statistics and Mathematics (First Class Honours) from the University of Colombo in 1984. He obtained his M.Sc. in Computer Science from Cardiff University, UK in 1989 and $\mathrm{PhD}$ in Computer Science from Cardiff University, UK in 1996. His $\mathrm{PhD}$ research was in the database field.

$\mathrm{He}$ is a professor and director of the University of Colombo School of Computing (UCSC), Sri Lanka and has served the university for over 25 years. He has served as a visiting researcher at Umea University, Stockholm University and University of New Mexico during 2008-2009. He has more than 60 publications in International peer reviewed Journals and Conference Proceedings. His interests are in statistics, database technology and e-learning.
Prof. Wikramanayake was awarded the most outstanding computer science graduate in 1984 and the University of Colombo research award in 2005. He is a senior member of IEEE and a council member of BCS, UK. He is the chair of BCS Sri Lanka Section and has held executive posts in IEEE Sri Lanka Section and the Computer Society of Sri Lanka. He has chaired conference organizing committees and is an associated editor of an international journal.

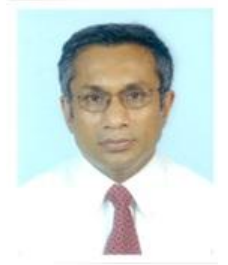

Dr. Damitha D. Karunartna obtained his B.Sc degree in Statistics and Mathematics (First Class Honours) from the University of Colombo in 1984. He obtained his M.Sc. in Computer Science from Swansea University, UK in 1990 and $\mathrm{PhD}$ in Computer Science from Cardiff University, UK in 1998. His $\mathrm{PhD}$ research was in the database and Ontology engineering field

Dr Karunaratna is a senior lecturer of the University Of Colombo School Of Computing and has more than 35 publications. His research interests are in Ontology Engineering, e-Learning and Geographic Information Systems.

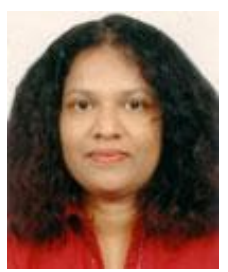

Dr. Dilkushi Senaratne Wettewe obtained he English honors degree from the Department of English, University of Kelaniya in 1998. She has completed her M.A in Linguistics and M.Phil in Linguistics from the University of Kelaniya. Dr Senaratne Wettewe read for her PhD at the Radboud University Nijmegen, in the Netherlands in 2009. Her $\mathrm{PhD}$ research was in the field of Contact Linguistics

(Sinhala and English code-mixing) and was completed under the supervision of Prof. Pieter Muysken, a veteran in the field. Her PhD thesis was published by the Netherlands Institute of Graduate Studies (LOT) in 2009. She has published many research abstracts and research papers in peer reviewed journals. Her interests are in Contact Linguistics, Bilingualism and Sociolinguistics.

She is the current head of the English Language Teaching Unit (ELTU) of the University of Kelaniya. She has been an academic staff member of the university since 2000. She was a member of the academic team that designed the University Test of English Language (UTEL) in Sri Lanka under Professor Ryhana Raheem. The UTEL benchmarks are now adopted by the entire university system in Sri Lanka. She was also the team leader of the PreOrientation course (POP) English Skills for New Entrants (2011 and 2012) conducted by the Ministry of higher Education and the HETC project Co-ordinator of the UDG English Activities of the University of Kelaniya, member of the Review Team of the UDG Grant Proposals by the HETC, member of the Review Team of the External Degree Program of the WB-HETC Project and Team leader of the Staff Development Course by the WB - HETC project. She is also the team leader of the UTEL test design team, conducted by the HETC. 